\title{
Effects of insulin-like growth factor-1 on random pattern skin flap survival in rats ${ }^{1}$
}

\author{
Nurten Turhan HaktanırI, Güray Yılmaz ${ }^{I I}$, Mehmet Fatih Bozkurt ${ }^{\mathrm{III}}$, Yavuz Demir ${ }^{\mathrm{IV}}$
}

DOI: http://dx.doi.org/10.1590/S0102-865020160080000003

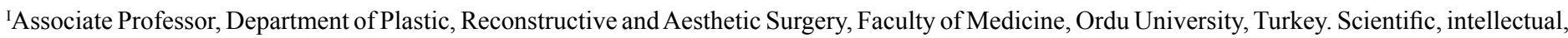
conception and design of the study; manuscript preparation and writing; final approval.

IIMD, Department of Plastic, Reconstructive and Aesthetic Surgery, Unye State Hospital, Ordu, Turkey. Acquisition, analysis and interpretation of data; technical procedures; statistical analysis; manuscript preparation.

IIIAssociate Professor, Department of Pathology, Faculty of Veterinary Medicine, Afyon Kocatepe University, Turkey. Histopathological examinations.

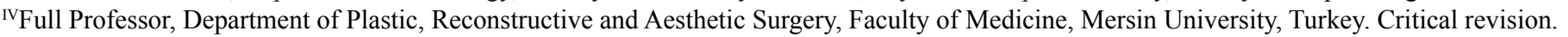

\begin{abstract}
PURPOSE: To investigate the effects of pharmacological delay with insulin-like growth factor-1 (IGF-1) on skin flap survival.

METHODS: Thirty Sprague-Dawley rats were submitted to dorsal skin flap $(3 \times 9 \mathrm{~cm})$. Seven days before the surgery, the animals were subdivided into three groups of 10 rats. In group 1 (controls), no injection was done. Seven days before the elevation, saline had been injected to the marked skin flap area in group 2 (sham group), and group 3 (experimental group) underwent a pharmacological delay with subcutaneous IGF-1 injections. On the seventh postoperative day, flap area was analyzed for survival. Tissue samples were obtained for histological and biochemical evaluations.

RESULTS: Survival rates were $43.55 \pm 16 \%, 21.40 \pm 8 \%$, and $43.12 \pm 14 \%$ in groups 1 , 2, and 3, respectively. Differences between group 2 and other groups were statistically significant. No significant difference was detected between all three groups for tissue or plasma vascular endothelial growth factor (VEGF) levels. There was no significant histological difference between groups.

CONCLUSION: Although a single injection of insulin-like growth factor-1 (IGF-1) did not significantly increase flap survival, its wound healing features are still encouraging and further meticulously planned studies, especially with repeated applications or controlled-release methods, and combinations with binding protein are required.
\end{abstract}

Key words: Insulin-Like Growth Factor I. Surgical Flaps. Survival. Skin. Rats. 


\section{Introduction}

One of the basic practices in plastic and reconstructive surgery is reparation of tissue defects caused by trauma, tumor, congenital abnormalities, or other incidents. The best functional and aesthetic results are achieved using flaps for this purpose. Flaps are classified as two subgroups according to the vascular supply: random-pattern skin flaps (supplied by subdermal-dermal plexus) and axial-pattern skin flaps (supplied by a direct cutaneous artery and vein located in subcutaneous tissue). Extending flap survival and decreasing amount of flap necrosis has been important subjects in surgical research. Surgical delay is the mostly used method for lessening the flap necrosis. Main disadvantages of delay are multiple interventions and long hospital stay. Many agents have been discussed for a single step delay process ${ }^{1}$.

Insulin-Like Growth Factor-1 (IGF-1) has growth stimulant effect via increasing the proliferation of many cell types including skeletal muscle, cartilage, bone, liver, kidney, neural, skin, hematopoietic, and lung cells. Circulating IGF-1 increases anabolic effects like protein synthesis, peripheral glucose uptake, glycogen synthesis, neuron survival, myelin synthesis, and bone formation ${ }^{2-7}$. In addition, it decreases some catabolic effects such as protein degradation in muscles ${ }^{8}$. In the present study, we aimed to detect experimentally whether the features of IGF-1 have any positive effect on the flap survival.

\section{Methods}

Support of institutional Scientific Research Projects Commission and approval of Local Ethical Board on Animal Studies were provided for this experimental study.

Thirty Sprague-Dawley rats ranging 250-300 grams were employed in the research. Standard room conditions were maintained with a temperature of $24^{\circ} \mathrm{C}, 12$ hours illuminated - 12 hours dark conditions and equal cage sizes. Two rats resided in each cage that had readily available rat food and tap water.

The experiment took place in three stages: 1- Chemical delay procedure stage: application of saline or IGF-1; 2- Surgical procedure stage: preparation of rat dorsal flap; and 3- Analyses stage: macroscopic analysis to report area measurements (planimetric measurement of flap), histological analysis, and biochemical analysis (tissue and blood sampling).

Randomly selected 10 rats formed three equal sized groups. Group 1 (control group): Flap elevated and sutured to its original donor area without application of any pharmacological agent. Group 2 (sham group): Flap area had been drawn and subcutaneous injections of $0,3 \mathrm{~mL}$ saline had been done to standard points before the flap elevation. Seven days after the injection, flap was elevated and sutured to its original position. Group 3 (experimental group): Flap area had been drawn and subcutaneous IGF-1 had been injected to standard points before the flap elevation. A total of 15 micrograms $/ 0,3 \mathrm{ml} \mathrm{IGF-1} \mathrm{was}$ administered. Seven days after the injection, flap was elevated and sutured to its original position.

\section{Preparation of IGF-1 and chemical delay}

A single IGF-1 bottle contains $1 \mathrm{mg}$ of human IGF1 in sterilized and lyophilized form. Before usage, IGF-1 was prepared with $1 \mathrm{ml}$ of distillated water. This $1 \mathrm{ml} \mathrm{IGF-1} \mathrm{which}$ was prepared for controlled injection and suitable formulation for rat doses was diluted with $19 \mathrm{ml}$ of distillated water. Hereby, 1000 micrograms of IGF-1 in $20 \mathrm{ml}$ of distillated water was prepared. It was administered subcutaneously to the experimental group rats as 15 micrograms $/ 0,3 \mathrm{ml}$ in a calculated dose of 6 micrograms $/ 100$ grams. Planned flap was divided in 6 equal pieces, and midpoints of each portion were determined as injection points (Figure 1).

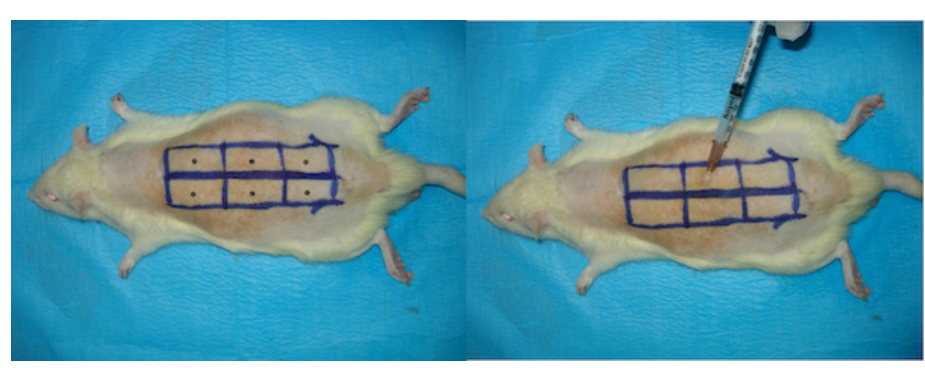

FIGURE 1 - Injection points (left) and injection of IGF-1 (right).

\section{Surgical procedure}

Anesthesia was accomplished with intramuscular injection of $100 \mathrm{mg} / \mathrm{kg}$ ketamine hydrochloride and $10 \mathrm{mg} / \mathrm{kg}$ xylazine hydrochloride to rats. After the subjects had anesthetized, trichotomy of donor areas were performed using an electrical razor. Rats were stabilized to the operation table in prone position. Povidone iodine was used for the cleaning of donor area. A $3 \times 9 \mathrm{~cm}$ of McFarlane flap modified by Khouri, containing all skin layers and panniculus carnosus was elevated with caudal base ${ }^{9}$. After the elevation, flap was re-sutured to the donor area by $4 / 0$ prolene suture with a sharp needle (Figure 2). 


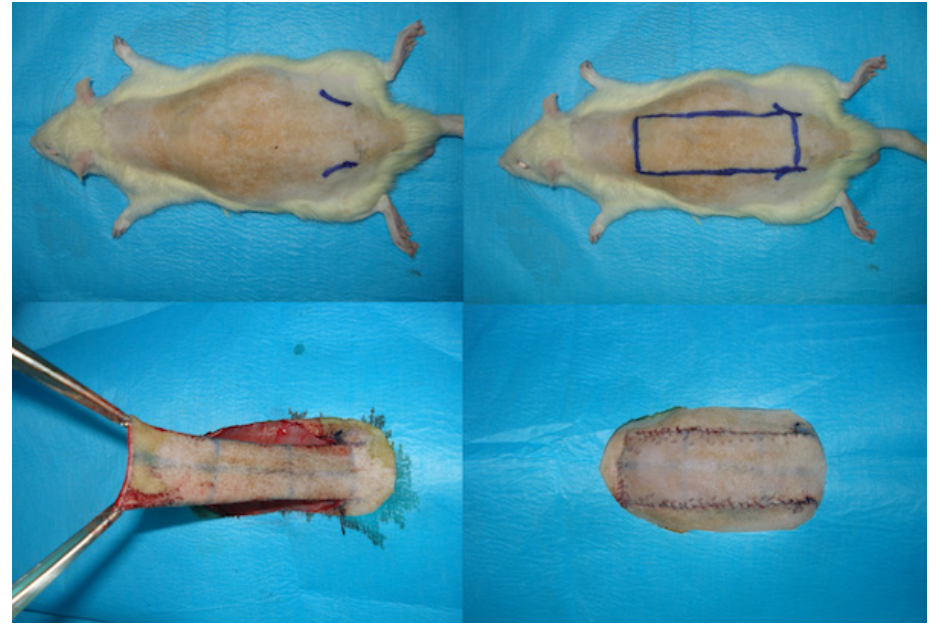

FIGURE 2 - Marking of iliac crests in the rat (upper left), planning of the dorsal McFarlane skin flap (upper right), flap elevation (lower left), and re-suturing of the flap (lower right).

\section{Analyses}

Flaps were followed up after the surgery; necrosis was arisen in the distal parts beginning from the second day. Demarcation of necrotic areas ended at postoperative seventh day. Rats were photographed with a digital camera (Sony DSC W 100, Sony Corporation, Tokyo, Japan). Tissue and blood samples were collected for histological and biochemical examinations.

Macroscopic analyses were carried out at postoperative seventh day in all groups. At the end of the seventh day, rats were placed to the table in prone position. All flaps were photographed from equal distances. Survived flap areas and whole flaps were measured by ImageJ program (Wayne Rasband, NIH) from the pictures. Survived flap area / whole flap was determined as percentiles (\%) (Figure 3). Because of the wound contracture, flap area at the end of the seventh day was smaller than its initial size. Even though flaps were contracted somewhat, percentile evaluation of survived flap area to whole flap ratio provided standardized results.

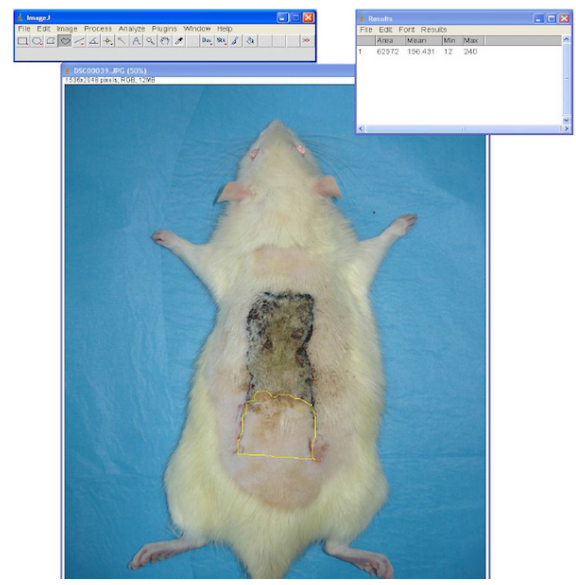

FIGURE 3 - Macroscopic measurement of survived areas on the flap.
Vascular endothelial growth factor (VEGF) levels were measured from the cardiac blood and $1 \mathrm{~cm}^{2}$ of tissue samples which had taken from flap demarcation line using Elisa method. Tissue samples were washed by cold saline and kept at $-20^{\circ} \mathrm{C}$ of temperature. Thereafter, they were homogenized with suitable buffer. VEGF level from the supernatant part was studied by Elisa method after the centrifugation of homogenized buffer.

For the histological examination, collected tissue samples were fixed in $10 \%$ phosphate buffered $(\mathrm{pH}$ 7.2) formaldehyde solution for 48 hours. Then, they were blocked in paraffin after alcohol and xylene applications. Specimens with 5-6 mm thickness from those blocks were taken to adhesive slides. Slides were stained by avidin-biotin-peroxidase complex (ABC) method. After the deparaffinization and dehydration processes, slides were transferred to phosphate buffered salty solution (PBS, $0.1 \mathrm{M}, \mathrm{pH}$ 7.4). To resolve the activity of endogenous peroxidase activity, slides were kept in $3 \%$ of $\mathrm{H}_{2} \mathrm{O}_{2}$ solution for 10 minutes. They were boiled in a $0.01 \mathrm{M}$ and $\mathrm{pH}=6.0$ of citrate buffer in a microwave to expose antigens. Specimens were limited with a hydrophobic pencil. Horse serum was applied for endogenous serum blocking and incubation was performed at $37^{\circ} \mathrm{C}$ for 10 minutes. To identify the vascular endothelium, rabbit anti-CD31 (Pecam-1) antibody with 1/500 dilution was dribbled to the tissues. They were washed after the incubation at $37^{\circ} \mathrm{C}$ for two hours in humidity chamber. Thereafter, $\mathrm{ABC}$ kit applications were started. Biotin conjugated with peroxidase was dribbled and incubated at $37^{\circ} \mathrm{C}$. Slides were washed and treated with the red coloring $\mathrm{ABC}$ peroxidase substrate. When the reaction was formed, they were taken to distillated water and the reaction was ended. Specimens were closed by lamella using aqueous glue and examined in light microscope. Vessels stained by CD31 antibody were counted morphometrically in 1 $\mathrm{mm}^{2}$ area with $\mathrm{x} 800$ magnification (Figure 4).

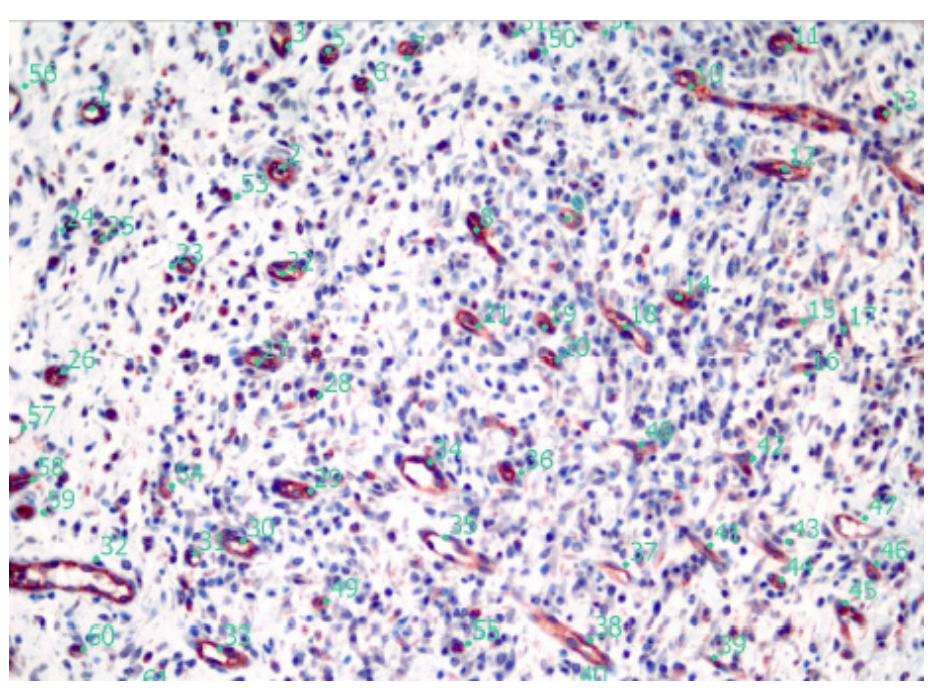

FIGURE 4 - Morphometric counting of CD31 antibody stained vessels in $1 \mathrm{~mm}^{2}(\mathrm{x} 800)$ 


\section{Euthanasia procedure}

Subcutaneous injection of morphine sulfate $(2.5 \mathrm{mg} / \mathrm{kg})$ was used for postoperative analgesia in all subjects. Thereafter, euthanasia was accomplished by cervical dislocation with subsequent intra-cardiac blood collection which was reserved for the biochemical analysis.

\section{Statistical analyses}

SPSS 18.0 Windows (SPSS Inc., Chicago, Illinois, USA) software was used for the statistical analyses. Area values among the groups (control, experiment and sham groups) were analyzed by using One-way ANOVA according to the results of Levene test and Shapiro-Wilk test for equality of variances and the normality assumption, respectively ( $p>0.05)$. Then, Tukey HSD (honest significant difference) multiple comparison test was applied to determine any further differences among the groups. Data were presented as sample size (n), mean with standard deviation, minimum and maximum values. Significance was evaluated at $p$ $<0.05$ for all tests.

\section{Results}

\section{Macroscopic analysis}

Photographs of groups are presented in Figure 5. Flap survival rates were $43.55 \pm 16 \%$ in group 1 (control group), $21.40 \pm 8 \%$ in group 2 (sham group), and $43.12 \pm 14 \%$ in group 3 (experiment group). No significant difference was detected between group 1 and $3(p=0.997)$. Differences between group 2 and group 3, and group 1 and group 2 were statistically significant $(p=0.001)$. Table 1 shows the statistical results of survived flap area / whole flap rates between groups as percentiles.
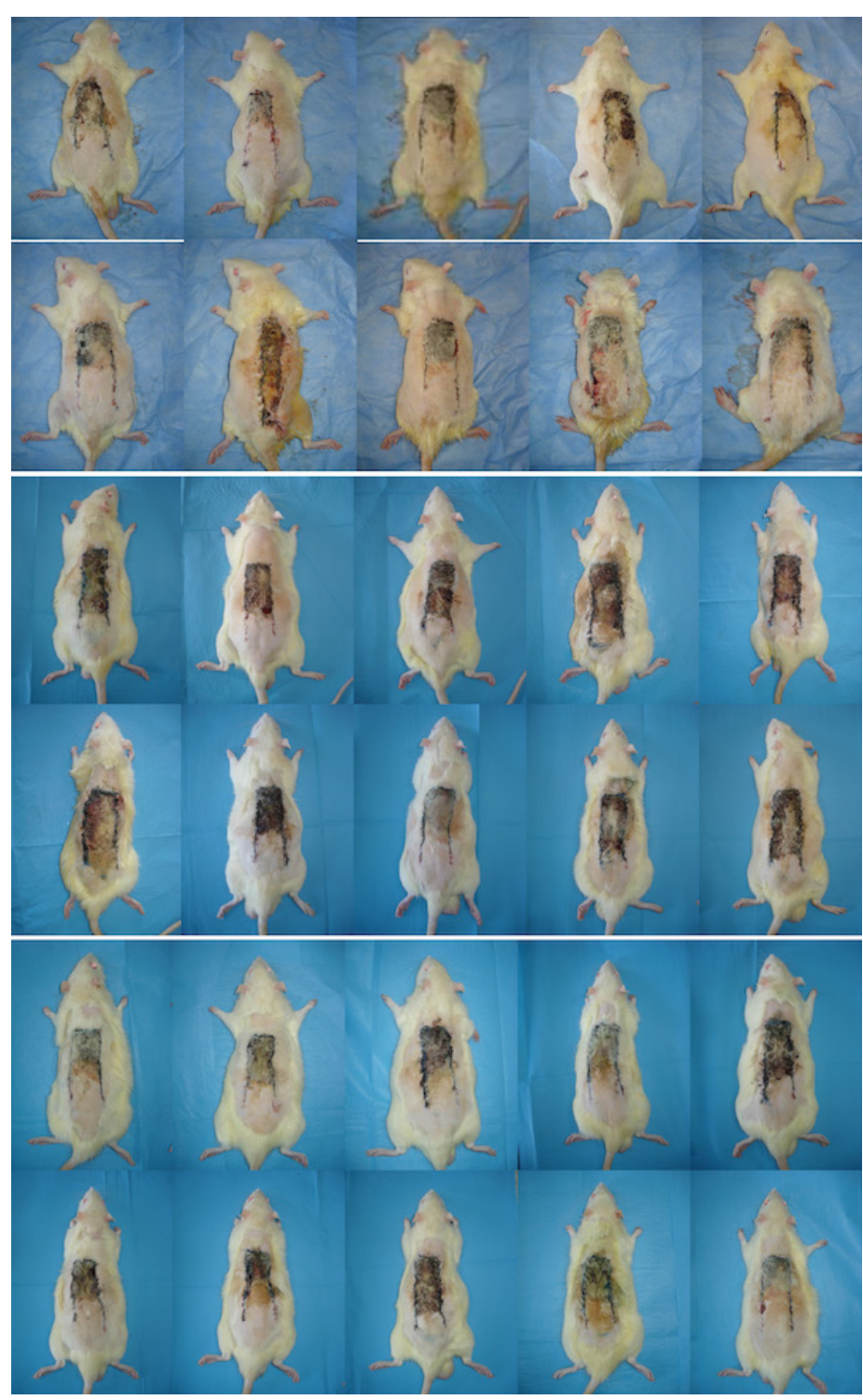

FIGURE 5 - Photographs of all three groups at the end of the experiment (upper: group 1, middle: group 2, and lower: group 3).

TABLE 1 - Results of survived flap area/whole flap rates between groups demonstrated as percentiles.

\begin{tabular}{ccccccc}
\hline & $\mathrm{n}$ & Mean & $\begin{array}{c}\text { Standard } \\
\text { Deviation }\end{array}$ & $\begin{array}{c}\text { Mini- } \\
\text { mum }\end{array}$ & $\begin{array}{c}\text { Maxi- } \\
\text { mum }\end{array}$ & $\begin{array}{c}\mathrm{p}- \\
\text { value }\end{array}$ \\
\hline Control & 10 & $43.55 \mathrm{a}$ & 16.30 & 13.03 & 74.55 & \\
Sham & 10 & $21.40 \mathrm{~b}$ & 8.09 & 10.14 & 34.59 & 0.001 \\
$\begin{array}{c}\text { Experi- } \\
\text { ment }\end{array}$ & 10 & $43.12 \mathrm{a}$ & 14.20 & 20.79 & 68.16 & \\
\hline
\end{tabular}

Different letters ( $a$ and $b$ ) indicates the differences between the same column.

\section{Biochemical analysis}

Tissue VEGF levels (pg/mg protein) were found $17.75 \pm 3.57 ; 18.65 \pm 4.84$; and $19.72 \pm 7.01$ in group 1,2 , and 3 , respectively. No statistically significant difference was detected 
between groups $(\mathrm{p}>0.05)$.

Plasma VEGF levels ( $\mathrm{pg} / \mathrm{ml})$ of groups were as follows: $6.38 \pm 2.09 ; 8.05 \pm 2.42$; and $6.23 \pm 2.02$ in group 1,2 , and 3 , respectively. We found no significant difference between groups.

\section{Histological analysis}

In Figure 6, selected samples of histological specimens are presented. Number of vessels were $73.10 \pm 21.86 ; 78.40 \pm$ 33.78; and $76.20 \pm 39.77$ in group 1, 2, and 3, respectively. There was no significant difference between groups $(\mathrm{p}>0.05)$.

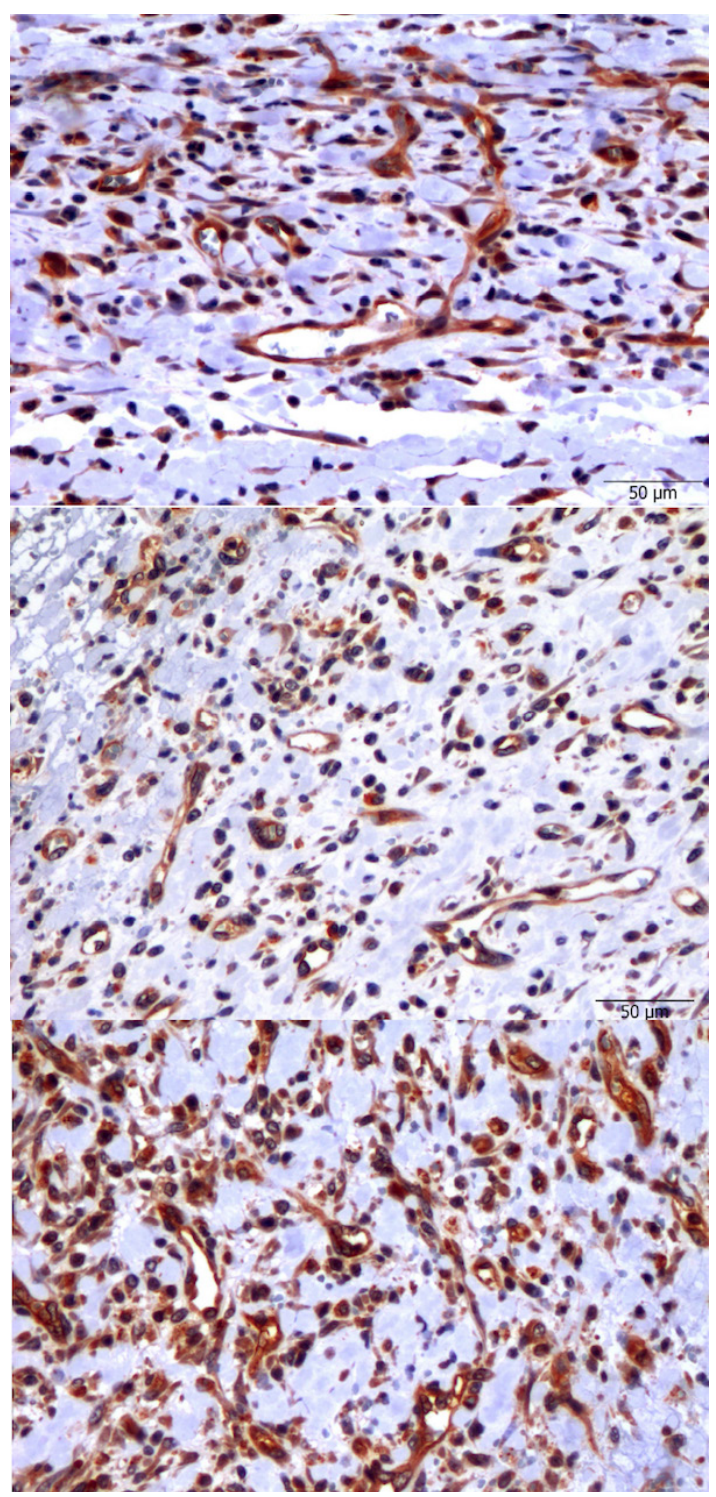

FIGURE 6 - Samples for histological specimens of groups (upper: group 1, middle: group 2, and lower: group 3).

\section{Discussion}

This experimental study evaluated the effects of InsulinLike Growth Factor-1 on Random Pattern Skin Flap Survival in
Rats. The injection of IGF-1 seven day before the operation did not significantly increase flap survival compared to controls in macroscopic, biochemical and histological examinations.

Previous studies observed IGF-1 increases re-epitelization by keratinocyte migration, collagen deposition by fibroblast proliferation, and granulation tissue by neovascularization ${ }^{10-12}$. Neovascularization is a known mechanism that advances flap survival in the delay process ${ }^{13}$. In the present study, we hypothesized that IGF-1 could pharmacologically provide neovascularization and increase the flap survival. We found no significant difference between experimental and control groups for skin flap survival, tissue and plasma VEGF levels, and vessel count on histological specimens. Saline usage lowered the flap survival. Conversely, IGF-1 usage did not decrease the flap survival.

IGF-I mediates the action of growth hormone in wound healing ${ }^{14}$. Previous studies demonstrated that circulating IGF-I has a minimal effect on wound healing and that the local IGF-I produced in wound tissue has more significance ${ }^{15}$. In addition, locally applied growth hormone increases the IGF-I mRNA concentration in the granulation tissue in vivo ${ }^{16}$. Lee et al..$^{14}$ examined whether or not locally applied growth hormone can accelerate wound-healing process, and whether or not it affects wound healing through endocrine or paracrine actions. They concluded that growth hormone can facilitate fibroblast proliferation and keratinocyte migration in vitro and it could be applied topically to accelerate wound healing. On this basis, we injected IGF-1 subcutaneously to increase its local effect on flap survival in the present study.

Kucuk et $a l .{ }^{17}$, based on effects of growth hormone on wound healing, investigated the effectiveness of infused recombinant human growth hormone on fistula closure and histopathological changes in healing tissue following pharyngocutaneous fistula formation in Sprague-Dawley rats after pharyngoesophagotomy. In their study, while control group received no treatment, experiment group were administered a subcutaneous injection of recombinant human growth hormone daily. They showed that it was effective for fistula closure by increasing collagen formation and epithelisation in a rat model. Similar to ours, the authors used a subcutaneous route of growth hormone application. However, they made the microscopical and macroscopical examinations on 14th day of the experiment. Limited time window in our study (seven days) might have yielded the insignificant results although the similarity of other methods with the above cited study.

$\mathrm{Gu}$ et $a .^{18}$ established subcutaneous injection of recombinant human growth hormone in their study with eight 
patients with enterocutaneous fistula. After 7 days, they showed that recombinant human growth hormone enhanced intestinal mucosal epithelial proliferation, protein synthesis and collagen formation in the immunohistochemical evaluation of endoscopic biopsies. Although the authors established a short period of observation like ours, they reported significant changes. That difference may be due to the the methodological difference, they used image analysis and immunohistochemical techniques to analyze the expression of proliferating cell nuclear antigen in intestinal mucosal epithelial cells in biopsy samples. Also, they measured body weights, nitrogen excretion, serum levels of total proteins, albumin, prealbumin, transferrin and fibronectin.

In the study of Lee et $a l .{ }^{14}$, fibroblast proliferation decreased above a specific concentration of growth hormone. They suggested that the effect of growth hormone on wound healing is dose dependent. Also, Li et al. ${ }^{19}$ demonstrated the dose dependency of growth hormone on fibroblasts. Failure of our study to demonstrate any positive effect of IGF-1 on flap survival may be resulted from the dose dependency of growth hormone effect. Apparently, further study on this issue is required.

Zhao et al. ${ }^{20}$ reported the effects on wound healing of IGF-I with and without insulin-like growth factor binding protein-1 in a rabbit ear dermal ulcer model under both nonischemic and ischemic conditions. They used IGF-I in varying single doses (1 to 43 micrograms) and in combination with varying molar ratios of the binding protein. The authors analyzed the wounds histomorphometrically on day 7 after wounding. They found that IGF-I or binding protein alone at varying doses did not have any effects on wound healing parameters. However, combination of IGF-I with the binding protein showed an increase of new granulation tissue in the nonischemic model with low doses, and in ischemic wounds with high doses. They concluded that insulinlike growth factor binding protein-1 modulates the effects of IGF-I in promoting wound healing in vivo and that the combination is a highly effective vulnerary compound with effects comparable in magnitude with other growth factors previously tested in this model. As Zhao et al. ${ }^{20}$, we administered IGF-1 in a single subcutaneous dose one week before the elevation of skin flap. In our study, lack of the combination of IGF-1 with insulin-like growth factor binding protein-1 seems to prohibit the any expected positive effect. Besides, not using controlled-release or gene transfer in the administration of IGF-1, which has a short halflife, might prevented any possible increase of flap survival in our study. Expensiveness and limited application facilities of gene transfer methods restrict its widespread use as a treatment in many countries including ours.
Transactions to be conducted to inflammation for pharmacological delay are built on a delicate balance. A surgical trauma in acutely elevated or delayed flaps creates an inflammatory response. This increases growth factors in the medium, which raise local blood flow and flap survival. Preoperative use of agents may raise inflammatory response for a successful pharmacological delay; thus, a delay-like effect and increased flap survival can be achieved. Anti-inflammatory agents that were used in the postoperative period (after flap elevation) eliminate the prolonged inflammation.

Diminishing edema can increase flap survival. Kurtz et $a .^{21}$ showed IGF-1 had an anti- inflammatory effect other than neutrophil migration and accelerated the healing duration. We used IGF-1 subcutaneously one week before the surgery. Therefore, anti- inflammatory effect of IGF-1 was formed before flap elevation. This premature anti-inflammatory effect might have decreased the desired inflammation and abolished the expected positive results.

\section{Conclusion}

Although a single injection of insulin-like growth factor-1 (IGF-1) did not significantly increase flap survival, its wound healing features are still encouraging and further meticulously planned studies, especially with repeated applications or controlled-release methods, and combinations with binding protein are required.

\section{References}

1. Karacaoglu E, Yuksel F, Turan SO, Zienowicz RJ. Chemical delay: an alternative to surgical delay experimental study. Ann Plast Surg. 2002Jul;49(1):73-80. PMID: 12142599.

2. Bakker AD, Gakes T, Hogervorst JM, de Wit GM, Klein-Nulend J, Jaspers RT. Mechanical stimulation and IGF-1 enhance mRNA translation rate in osteoblasts via activation of the AKT-mTOR pathway. J Cell Physiol. 2016 Jun;231(6):1283-90. doi: 10.1002/ jcp. 25228 .

3. Xian L, Wu X, Pang L, Lou M, Rosen CJ, Qiu T, Crane J, Frassica F, Zhang L, Rodriguez JP, Xiaofeng Jia, Shoshana Yakar, Shouhong Xuan, Argiris Efstratiadis, Mei Wan, Xu Cao. Matrix IGF-1 maintains bone mass by activation of mTOR in mesenchymal stem cells. Nat Med. 2012 Jul;18(7):1095-101. doi: 10.1038/nm. 2793.

4. Clemmons DR. Metabolic actions of insulin-like growth factor-I in normal physiology and diabetes. Endocrinol Metab Clin North Am. 2012 Jun;41(2):425-43. doi: 10.1016/j.ecl.2012.04.017.

5. Ceafalan LC, Popescu BO, Hinescu ME. Cellular players in skeletal muscle regeneration. Biomed Res Int. 2014;2014:957014. doi: 10.1155/2014/957014.

6. Kawai M, Rosen CJ. The insulin-like growth factor system in bone: basic and clinical implications. Endocrinol Metab Clin North Am. 2012 Jun;41(2):323-33. doi: 10.1016/j.ecl.2012.04.013. 
7. Fortier LA, Barker JU, Strauss EJ, Mccarrel TM, Cole BJ. The role of growth factors in cartilage repair. Clin Orthop Relat Res. 2011 Oct;469(10):2706-15. doi: 10.1007/s11999-011-1857-3.

8. Li BG, Hasselgren PO, Fang CH, Warden GD. Insulin-like growth factor-I blocks dexamethasone-induced protein degradation in cultured myotubes by inhibiting multiple proteolytic pathways: 2002 ABA paper. J Burn Care Rehabil. 2004 Jan-Feb;25(1):112-8. PMID: 14726748.

9. Khouri RK, Angel MF, Edstrom LE. Standardizing the dorsal rat flap. Surg Forum. 1986 37:590-4.

10. Daian $\mathrm{T}$, Ohtsuru A, Rogounovitch $\mathrm{T}$, Ishihara H, Hirano A, Akiyama-Uchida Y, Saenko V, Fujii T, Yamashita S. Insulin-like growth factor-I enhances transforming growth factor-beta-induced extracellular matrix protein production through the P38/activating transcription factor-2 signaling pathway in keloid fibroblasts. J Invest Dermatol. 2003 Jun;120(6):956-62. PMID: 12787120.

11. Haase I, Evans R, Pofahl R, Watt FM. Regulation of keratinocyte shape, migration and wound epithelialization by IGF-1- and EGFdependent signaling pathways. J Cell Sci. 2003 Aug 1;116(Pt 15):3227-38. PMID: 12829742.

12. Ding J, Wirostko B, Sullivan DA. Human growth hormone promotes corneal epithelial cell migration in vitro. Cornea. 2015 Jun;34(6):686-92. doi: 10.1097/ICO.0000000000000418.

13. Zhang F, Lineaweaver W. Acute and sustained effects of vascular endothelial growth factor on survival of flaps and skin grafts. Ann Plast Surg. 2011 May;66(5):581-2. doi: 10.1097/ SAP.0b013e3182057376

14. Lee SW, Kim SH, Kim JY, Lee Y. The effect of growth hormone on fibroblast proliferation and keratinocyte migration. J Plast Reconstr Aesthet Surg. 2010 Apr;63(4):e364-9. doi: 10.1016/j. bjps.2009.10.027.

15. Dunaiski V, Belford DA. Contribution of circulating IGF-1 to wound repair in GH-treated rats. Growth Horm IGF Res. 2002 Dec;12(6):381-7. PMID: 12423623.

16. Steenfos HH, Jansson J-O. Growth hormone stimulates granulation tissue formation and insulin-like growth factor-I gene expression in wound chambers in the rat. J Endocrinol. 1992 Feb;132(2):293-8. PMID: 1311749.

17. Kucuk N, Sari M, Midi A, Yumusakhuylu AC, Findik O, Binnetoglu A. Effectiveness of recombinant human growth hormone for pharyngocutaneous fistula closure. Clin Exp Otorhinolaryngol. 2015 Dec;8(4):390-5. doi: 10.3342/ceo.2015.8.4.390.
18. Gu GS, Ren JA, Li N, Li JS. Effects of recombinant human growth hormone on enterocutaneous fistula patients. World J Gastroenterol. 2008 Nov; 14(44):6858-62. PMID: 19058314.

19. Li JX, Liu XS, Tang H, Zhou X, Huang YS. Influence of some topical antibiotics and FGF2, EGF and rhGH on the biological characteristics of fibroblasts in vitro. Zhonghua Shao Shang Za Zhi. 2006;Feb;22(1):33-7. PMID: 16680959.

20. Zhao LL, Galiano RD, Cox GN, Roth SI, Mustoe TA. Effects of insulin-like growth factor-I and insulin-like growth factor binding protein-1 on wound healing in a dermal ulcer model. Wound Repair Regen. 1995 Jul-Sep;3(3):316-21. PMID: 17173558.

21. Lutz BS, Wei FC, Ma SF, Chuang DC. Effects of insulin-like growth factor-1 in motor nerve regeneration after nerve transection and repair vs. nerve crushing injury in the rat. Acta Neurochir (Wien). 1999;141(10):1101-6. PMID: 10550657.

\section{Correspondence:}

\section{Nurten Turhan Haktanır}

Department of Plastic, Reconstructive and Aesthetic Surgery

Faculty of Medicine, Ordu University, Turkey

Phone: +90 4522265214

Fax: +904522265228

nurth70@yahoo.com

Received: Apr 03, 2016

Review: Jun 08, 2016

Accepted: July 11, 2016

Conflict of interest: none

Financial source: Scientific Research Council, Afyon Kocatepe University (grant number 08.TIP.27)

${ }^{1}$ Research performed at Department of Plastic, Reconstructive and Aesthetic Surgery, Faculty of Medicine, Afyon Kocatepe University, Turkey. 